\title{
Sleep-Disordered Breathing and Idiopathic Normal-Pressure Hydrocephalus: Recent Pathophysiological Advances
}

\author{
Gustavo C. Román ${ }^{1,2}$ - Robert E. Jackson ${ }^{3,4}$ - Steve H. Fung ${ }^{5,6} \cdot$ Y. Jonathan Zhang ${ }^{7,8}$ • Aparajitha K. Verma ${ }^{1,2,9}$
}

Published online: 29 May 2019

(C) The Author(s) 2019

\begin{abstract}
Purpose of Review Idiopathic normal-pressure hydrocephalus (iNPH) is characterized clinically by ventriculomegaly, abnormal gait, falls, incontinence, and cognitive decline. This article reviews recent advances in the pathophysiology of iNPH concerning sleep-disordered breathing (SDB) and glymphatic circulation during deep sleep.

Recent Findings The authors found iNPH frequently associated with obstructive sleep apnea (OSA). A critical factor in iNPH is intracranial venous hypertension delaying drainage of cerebrospinal fluid (CSF) into the cerebral venous sinuses. CSF-venous blood circulates in the jugular veins and finally drains into the heart. During SDB, repeated reflex attempts to breathe induce strong respiratory efforts against a closed glottis thereby increasing the negative intrathoracic pressure. This causes atrial distortion and decreases venous return to the heart resulting in retrograde intracranial venous hypertension. Additionally, repeated awakenings from OSA impede sleep-associated circulation of interstitial CSF into the glymphatic circulation contributing to hydrocephalus.
\end{abstract}

Summary Sleep has become a critical element in the cognitive changes of aging including iNPH.

Keywords Cerebral venous circulation · Glymphatic system · Normal-pressure hydrocephalus · Obstructive sleep apnea Sleep-disordered breathing · Vascular risk factors

\section{Introduction}

Sleep is rapidly becoming the new frontier for the study of cognition, particularly in neurodegenerative dementias of aging [1•]. Normal sleep is critical for consolidation of memory and other cognitive functions; aging is associated with changes in sleep pattern that mediate age-related cognitive decline [2-4]. Sleep-disordered breathing

This article is part of the Topical Collection on Sleep

Gustavo C. Román

GCRoman@houstonmethodist.org

1 Department of Neurology, Methodist Neurological Institute and Houston Methodist Hospital Research Institute for Academic Medicine, Houston, TX, USA

2 Department of Neurology, Weill Cornell Medical College, Cornell University, New York, NY, USA

3 Department of Medicine, Houston Methodist Hospital and Houston Research Institute for Academic Medicine, Houston, TX, USA

4 Department of Medicine, Weill Cornell Medical College, Cornell University, New York, NY, USA
(SDB), caused mainly by obstructive sleep apnea (OSA), affects daytime functioning by impairing memory, attention, and executive functions [5-7]. Numerous population-based studies $\left[8-11,12^{\circ}\right]$ have shown that OSA is associated with up to $26 \%$ higher risk of cognitive impairment [12•], particularly in the elderly. Also, abnormal sleep has been associated with increased risk of Alzheimer disease (AD) [13-15].

5 Department of Radiology MRI Core, Houston Methodist Hospital and Methodist Research Institute for Academic Medicine, Houston, TX, USA

6 Department of Radiology Weill Cornell Medical College, Cornell University, New York, NY, USA

7 Department of Neurosurgery, Methodist Neurological Institute and Houston Methodist Hospital Research Institute for Academic Medicine, Houston, TX, USA

8 Department of Neurosurgery, Weill Cornell Medical College, Cornell University, New York, NY, USA

9 Sleep Laboratory Houston Methodist Hospital, Houston, TX, USA 
Idiopathic normal-pressure hydrocephalus (iNPH) [16•] is a treatable form of dementia in the elderly with an average age of onset above 70 years. Approximately 700,000 persons might have iNPH in the USA in comparison with about 400,000 cases of multiple sclerosis. Unfortunately, although $60-80 \%$ of iNPH patients improve with shunt surgery, only a minority is diagnosed and treated. Patients with iNPH often have multiple vascular risk factors [17] including hypertension, diabetes, hyperlipidemia, smoking, hyperhomocysteinemia, coronary disease, stroke, and excessive body weight. Sleep studies have seldom been performed in patients affected by iNPH; therefore, SDB and OSA are rarely mentioned among the vascular risk factors [17]. This is due in part to the fact that both iNPH and OSA are largely underdiagnosed clinical conditions. However, with routine use of sleep questionnaires and polysomnography, we were able to demonstrate that SDB and iNPH are commonly associated, ranging in frequency from 65 to $90 \%$ [18••]. The latter observation serves as the basis for the present update.

\section{Clinical Manifestations of iNPH}

The communicating hydrocephalus of iNPH is nonobstructive and characterized by enlargement of the cerebral ventricles with an Evans index greater than 0.30 (i.e., the ratio of the widest diameter of the frontal horns divided by the widest brain diameter on the same axial slice). Evans index values $\geq 0.33$ indicate ventriculomegaly [19]. Other imaging features on magnetic resonance imaging (MRI) are a callosal angle $\geq 40^{\circ}$ but $<90^{\circ}$ [20] and narrowing of the sulci and subarachnoid spaces over the high convexity with enlarged Sylvian fissures, a feature called "disproportionately enlarged subarachnoid space hydrocephalus" (DESH) [21, 22]. Increased cerebrospinal fluid (CSF) stroke volume $>42 \mu \mathrm{L}$ or pulsatile flow rates $>18 \mathrm{~mL} / \mathrm{min}$ in the aqueduct of Sylvius on MRI, synchronized to the heartbeat for quantification, are considered good prognostic indicators for CSF shunting [23].

The clinical triad of iNPH includes cognitive loss, abnormal gait, and urinary incontinence. The cognitive problems include memory deficits and executive dysfunction predominantly frontal in nature. In their original description, Hakim and Adams [24•] mentioned, "psychomotor retardation ... lack of impulsivity, expressed as apathy, disinterest, and lack of spontaneity." Nevertheless, progressive gait difficulty and frequent falls may be the only manifestation of iNPH, without concurrent cognitive decline.

Gait imbalance resulting in frequent falls is a constant manifestation of iNPH [25]. Leg involvement is probably due to effects of ventriculomegaly on the tracts arising from the cortical representation of the lower limbs in the medial aspect of the primary motor cortex. Walking is described as wobbly, staggering, or drunken. Patients tend to fall without any obstacles, stumbling on minor floor irregularities, or while negotiating stairs and curbs. Gait initiation is slow and the feet appear to be "glued" to the floor or "magnetized." Patients walk very slowly, with shuffling short steps. With the eyes closed, both the postural instability and the unsteadiness of gait increase markedly, indicating that both apraxia of gait and ataxia of leg movements in the vertical direction are present. Turning becomes precarious and is usually done by pivoting in one leg, i.e., the so-called compass sign [25]. At this point, patients usually require a cane or a walker to ambulate and are at very high risk of falls resulting in hip fractures and traumatic subdural hematomas. Hydrocephalus is often diagnosed in the emergency room during the evaluation of an elderly patient who sustained a fall. Falls among older adults are a major public health problem and by 2030 the number of fatalities is projected to reach 100,000 per year with an associated cost of $\$ 100$ billion as a result of fractures, head injury, and other traumatic lesions [26].

The incontinence of sphincters is usually a manifestation of frontal dysfunction. According to Hakim and Adams [24•]: “ $\ldots$ the patient being unaware of the contents of bladder and bowel is incapable of making any arrangement for the somewhat precipitate action of these organs." Urinary incontinence is the second most common symptom of iNPH after gait problems and falls but it is often discounted as being the result of omnipresent prostate problems in aged men or an exacerbation of chronic bladder stress incontinence in elderly women. Urinary incontinence results in recurrent urinary tract infections and fatal septicemia. Frontal-type stool incontinence is less common but it also occurs in iNPH [25].

\section{Obstructive Sleep Apnea}

OSA is the most prevalent form of SDB in adults [27•] affecting about 20 million Americans. SDB is an independent vascular risk factor - seldom diagnosed - that increases significantly the risk of cardiovascular complications [28, 29]. OSA was first reported by Gastaut and collaborators [30•] in a Pickwickian man with hypersomnia secondary to repeated airway obstructions by the tongue during sleep. Despite its prevalence, OSA remains grossly underdiagnosed: A recent systematic review of 24 population-based sleep studies using PSG among adults in the general population [31] found a worldwide increase in the prevalence of OSA. Severe OSA in older age groups reached an overall prevalence of $36 \%[32$, 33]. A major risk factor for OSA is obesity, defined as a body mass index (BMI) $>30 \mathrm{~kg} / \mathrm{m}^{2}$ [34]. OSA is a treatable cause of hypertension [35, 36], type 2 diabetes mellitus [37], and cardiovascular disease $[28,29]$, particularly atrial fibrillation [38-40], as well as pulmonary hypertension [41, 42], stroke, and transient ischemic attacks [43]. 


\section{Effects of OSA in Sleep}

Early recordings of intracranial pressure during sleep demonstrated variations in CSF pressure during different sleep stages [44-46]. Table 1 provides a chronological summary of studies demonstrating elevation of intracranial pressure linked to the episodes of apnea in patients with OSA and concurrent iNPH. Several groups confirmed the presence of apnea-associated waves of increased CSF pressure (Lundberg B-waves) during rapid eye movement (REM) sleep [47-60].

Apneas were preceded by a decrease in both arterial pressure and intracranial pressure and by increasing central venous pressure; this was reversed during the apnea along with lowering arterial $\mathrm{SaO}_{2}$ and increase $\mathrm{SaCO}_{2}$. At the termination of the apnea, a steep increase in arterial and intracranial pressures occurred. Intermittent CSF pressure values as high as $750 \mathrm{~mm}$ $\mathrm{H}_{2} \mathrm{O}$ were measured [54], well above the normal CSF pressure range (100-180 $\mathrm{mm} \mathrm{H}_{2} \mathrm{O}$ or 8-15 $\mathrm{mmHg}$ ), causing stress on the ventricular ependymal lining, the walls of the ventricles, and the surrounding brain structures.

It should be remembered that the CSF circulation is called "the third circulation" [61] because CSF production is linked to systemic arterial pressure and CSF reabsorption to the central venous pressure. This explains the interaction described above between respiration and intracranial pressure. CSF is produced by the choroid plexus inside the cerebral ventricles from arterial blood at rates dependent on systolic blood pressure.

After circulating in the ventricles and around the cerebral and spinal subarachnoid space, CSF is reabsorbed into the intracranial venous circulation at the level of the Pacchionian granulations that protrude into the lumen of the cerebral venous sinuses, particularly into the superior longitudinal sinus. The CSF-venous blood admixture drains into the internal jugular veins, then the brachiocephalic or innominate veins, the superior vena cava, and finally into the right atrium and the heart.

Table 1 Early studies on the effects of obstructive sleep apnea on intracranial pressure, $\mathrm{SaO}_{2}$, and $\mathrm{PaCO}_{2}$

\begin{tabular}{|c|c|}
\hline Author/year & Findings \\
\hline Meyer et al., 1961 [47] & $\begin{array}{l}\text { Pickwickian patient with papilledema, excessive sleepiness, hypoxemia, and hypercapnia; } \\
\text { lumbar puncture showed elevation of CSF pressure to } 480 \mathrm{~mm} \mathrm{H}_{2} \mathrm{O} \text {. }\end{array}$ \\
\hline $\begin{array}{l}\text { Lugaresi et al., } \\
1978[48]\end{array}$ & $\begin{array}{l}45 \text { OSA subjects: Arterial hypertension in } 1 / 3 \text { cases; all had transient hypoxemia and elevated } \mathrm{PaCO}_{2} \text { with sleep } \\
\text { apnea episodes; values worsened during REM sleep. }\end{array}$ \\
\hline Iijima et al., 1979 [49] & OSA: Arterial blood gases showed transient hypoxemia and hypercapnia with apnea episodes. \\
\hline $\begin{array}{l}\text { Kaneda et al., } 1983[50] \\
\text { Kuchiwaki et al., } \\
1983 \text { [51] }\end{array}$ & $\begin{array}{l}\text { First described the association of OSA and NPH. ICP recording in patients with NPH showed increased ICP with } \\
\text { presence of Lundberg B-waves with each apnea episode. }\end{array}$ \\
\hline $\begin{array}{l}\text { Kuchiwaki et al., } \\
1984 \text { [52]; } 1988 \text { [53] }\end{array}$ & $\begin{array}{l}17 \text { patients with NPH and OSA showed elevation of CSF pressure during sleep apnea events. } \\
\text { CSF shunting in } 13 \text { cases failed to improve the hypoxemia and hypercapnia observed with OSA. } \\
\text { Authors suggested that OSA contributes to progression and worsening of hydrocephalus. }\end{array}$ \\
\hline Sugita et al., 1985 [54] & $\begin{array}{l}3 \text { patients with OSA: Marked increase of CSF pressure }\left(50-750 \mathrm{~mm} \mathrm{H}_{2} \mathrm{O}\right) \text { measured at lumbar level following each } \\
\text { episode of OSA/hypopnea. Longer apneas during REM sleep resulted in worse } \mathrm{SaO}_{2} \text { decreases and higher } \\
\text { increases of CSF pressure. }\end{array}$ \\
\hline Jennum and Børgesen, 1989 [55] & $\begin{array}{l}6 \text { OSA patients (none with NPH): Each apnea event increased ICP. ICP at rest was high (> } 15 \mathrm{mmHg} \text { ) and also in the } \\
\text { morning }(20 \cdot 7 \mathrm{mmHg}) \text {. While asleep, all patients developed apnea-associated elevated ICP. }\end{array}$ \\
\hline Pasterkamp et al., 1989 [56] & $\begin{array}{l}1 \text { patient with hydrocephalus treated with CSF shunt developed OSA years later: Rising intraventricular ICP up to } \\
50 \mathrm{~cm} \mathrm{H} \mathrm{H}_{2} \mathrm{O} \text { occurred with each episode of apnea probably contributing to worsening syringomyelia. }\end{array}$ \\
\hline McNamara et al., 1992 [57] & $\begin{array}{l}\text { NPH symptoms worsened with nasal CPAP in } 1 \text { patient with NPH; treatment of NPH with VPS allowed use of CPAP } \\
\text { with clinical improvement. CPAP and PEEP increase central venous pressure decreasing venous and CSF outflow, } \\
\text { causing increased ICP. }\end{array}$ \\
\hline Krauss et al., 1995 [58] & $\begin{array}{l}\text { In } 13 \mathrm{NPH} \text { patients, sleep apneas caused elevation of intraventricular ICP with Lundberg B-waves. } \\
\text { Frequency of B-waves was higher during REM sleep and sleep stage } 2 \text {. }\end{array}$ \\
\hline Kristensen et al., 1998 [59] & $\begin{array}{l}\text { Sleep-disordered breathing is very common in NPH: OSA was documented in } 65 \% \text { or 11/17 NPH patients. } \\
\text { VPS failed to ameliorate sleep-disordered breathing in patients with NPH. } \\
\text { OSA causes additional cognitive dysfunction in NPH patients. }\end{array}$ \\
\hline Tsunoda et al., 2002 [60] & $\begin{array}{l}\text { Using MRI, ventricular volume and intracranial CSF volume were increased in } 17 \text { patients with NPH; } \\
\text { compared with controls, brain atrophy was also present in NPH patients. }\end{array}$ \\
\hline
\end{tabular}

Abbreviations: CPAP, continuous positive airway pressure; $C S F$, cerebrospinal fluid; $I C P$, intracranial pressure; $M R I$, magnetic resonance imaging; $N P H$, normal-pressure hydrocephalus; $\mathrm{OSA}$, obstructive sleep apneas; $\mathrm{PaCO}_{2}$, arterial partial pressure of carbon dioxide; $P E E P$, positive end-expiratory pressure; $R E M$, rapid eye movement; $\mathrm{SaO}_{2}$, arterial oxygen saturation; $V P S$, ventriculoperitoneal shunt 


\section{SDB-Induced Intracranial Venous Hypertension}

Figure 1 summarizes the main pathophysiological cardiovascular mechanisms linking sleep apneas and hydrocephalus. Fragmentation of the sleep architecture induced by apneas reduces glymphatic circulation and further contributes to iNPH.

\section{Cardiovascular Mechanisms}

In 2008, Williams [62] proposed that the main pathogenic mechanism in hydrocephalus is intracranial venous hypertension whereby the increased intracranial venous pressure hinders CSF absorption through the arachnoid villae in the dural sinuses resulting in excessive accumulation of intracranial CSF. A number of studies have confirmed the postulated venous hypertension hypothesis [63-66]. The cardiovascular and metabolic mechanisms resulting from OSA capable of inducing intracranial venous hypertension are summarized in Table 2.

Obstructed breathing during sleep causes marked increase of the negative intrathoracic pressure and hypoxemia. The interruption of ventilation in OSA is usually due to relaxation of pharyngeal and tongue muscles causing airway obstruction at the pharynx [67-69]. This occurs most often during the global loss of muscle tone and relaxation of muscles typical of slow-wave NREM and REM sleep. The extrinsic muscles of the tongue (genioglossus, geniohyoid) insert on the mandible's inner surface. Slow-wave and REM sleep cause the jaw to drop and the tongue to fall back blocking the airway. Concurrent contracture of pharyngeal constrictor muscles further closes the airway. Supine and open-mouth sleepers from chronic obstruction of nasal passages tend to have more apneas than those who sleep with a closed mouth or in lateral decubitus.

Hypoxemia occurs as a result of the interruption of respiration (apnea or hypopnea), lowering of $\mathrm{PaO}_{2}$ with concomitant hypercapnia from $\mathrm{CO}_{2}$ retention, elevation of $\mathrm{PaCO}_{2}$, and respiratory acidosis $[69,70]$. Patients with severe OSA (Apnea-Hypopnea Index, AHI $\geq 30 / h$ ) may exhibit $>60$ apneas per hour of sleep (i.e., $>1$ apnea/min) with severe metabolic consequences [66-71].

The main stimulus for respiratory inspiration is the activation by the low $\mathrm{PaO}_{2}$ of carotid and aortic body chemoreceptors and brainstem respiratory chemoreceptors responding to increased $\mathrm{PaCO}_{2}$ and lower blood $\mathrm{pH}$ as a result of respiratory acidosis. The net result of the stimulation of chemoreceptors is the activation of rostral pontine respiratory neurons that in turn stimulate firing of neurons in the solitary tract nucleus and the dorsal medullary respiratory group and ventral group in the nucleus ambiguus $[72,73]$.

Inspiratory impulses are carried by the phrenic and intercostal nerves, stimulating motor activity of the diaphragm, respiratory inspiratory muscles, and pharyngeal dilator muscles. The contraction of diaphragm and intercostal muscles results in expansion of the thoracic cavity. The inspiratory effort concludes when pulmonary stretch afferences stimulate the pontine apneustic center that in turn inhibits medullary inspiratory neurons $[72,73]$.

These reflex attempts to breathe cause intermittent, often violent, and strenuous respiratory efforts that involve chest and abdominal musculature trying to overcome the obstruction of the airway to restore airflow. This is the Mueller maneuver (the opposite of Valsalva's) that generates severely negative intrathoracic pressure $(-60$ to $-80 \mathrm{mmHg})$ [68-71]. The resulting atrial distortion is a major risk factor for atrial fibrillation [67-69, 74].

Suffocation is the end result of these unsuccessful respiratory efforts to improve oxygenation producing an acute stress reaction with microarousals, awakening and disruption of sleep due to the sympathetic (adrenergic) outburst resulting, among other effects, in arterial hypertension, peripheral vasoconstriction, hyperglycemia, and hypercoagulability [75-77]. OSA is the commonest cause of drug-resistant secondary hypertension [78].

Subsequent reoxygenation and recirculation of hypoxic and acidotic blood worsens hypoxemia and results in generation of reactive oxygen species (ROS), C-reactive protein (CRP), homocysteine (Hcy), and other inflammatory factors $[79,80]$. The recirculation of anoxic and acidotic blood has major inflammatory effects and explains the increased risk of coronary artery disease, stroke, and small-vessel cerebrovascular disease found in patients with OSA [66, 81].

The apnea-induced negative intrathoracic pressure opposes the venous return to the heart resulting in elevation of venous pressure in the superior vena cava and internal jugular vein system. The authors propose that the end result of untreated SDB is intracranial venous hypertension. This leads to reduction of the normal drainage of CSF into the superior sagittal sinus and other dural sinuses eventually causing progressive accumulation of CSF inside the ventricles, ventriculomegaly, and symptomatic NPH.

The statistically significant association of OSA with NPH is relatively novel $\left[18^{\circ}\right]$ but the physiopathological vascular and metabolic mechanisms have been amply supported in the literature [66-71, 74-80]. For instance, pulmonary hypertension is a well-known effect of OSA [82] and positive endexpiratory pressure (PEEP) [83-85] can increase central venous pressure, decreasing outflow and elevating intracranial CSF pressure. Frydrychowski et al. [86] showed that acute increases in jugular vein pressure induce elevation of intracranial CSF pressure. Lee et al. [87] postulated a similar mechanism to explain the induction of papilledema in obese subjects with pseudotumor cerebri [87] particularly in the presence of OSA [88]. 


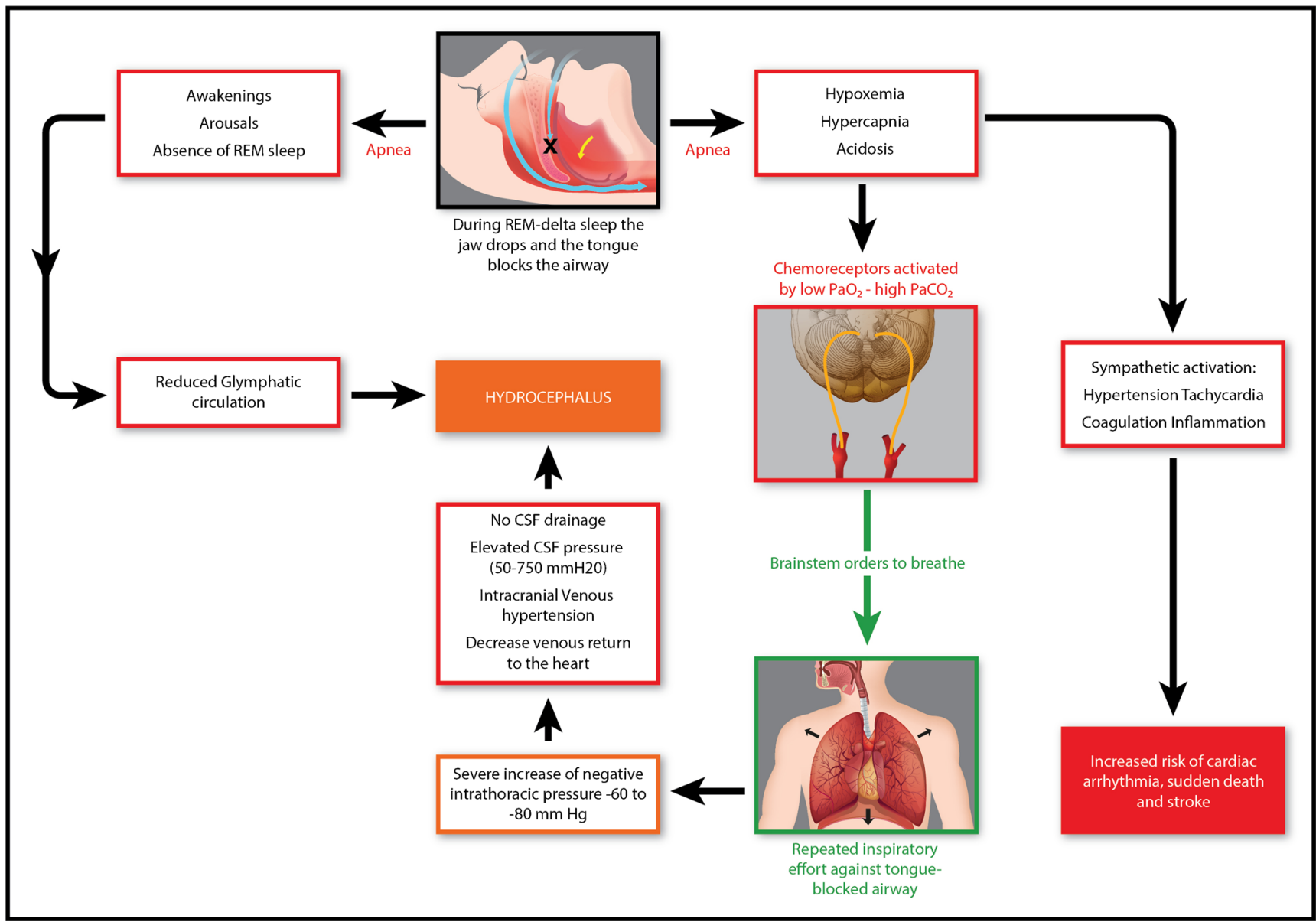

Fig. 1 In subjects with SDB, sleep apneas occur more frequently during deep sleep stages, i.e., REM sleep and delta sleep. Muscle paralyses typical of deep sleep stages lead to opening of the mouth and relaxation of tongue muscles (top central image). The resulting apnea (right arrow) causes hypoxemia, hypercapnia, and acidosis that activate arterial chemoreceptors. In turn, this activation is answered by respiratory brainstem nuclei, which order the inspiratory muscles to inhale (downward green arrow). Repeated inspiratory movements against the closed airway cause severe increase of negative intrathoracic pressure $(-60$ to $-80 \mathrm{mmHg})$, decrease of venous return to the heart, intracranial venous hypertension, absence of CSF drainage into the

\section{Alterations of Glymphatic Circulation in iNPH}

The glymphatic (glial-lymphatic) pathway of the brain $[89 \bullet \cdot, 90 \bullet$ ] directs the flow of CSF along arterial perivascular spaces into the brain interstitial spaces, facilitated by aquaporin 4 (AQP4) water channels [91, 92]. CSF circulation in the glymphatic system in rodents increases twofold during deep delta sleep and correlates with increase in AQP4 [90••]. The flow of CSF reaches the venous perivascular and perineuronal spaces, ultimately draining into meningeal and cervical lymphatic vessels. The overall function of the glymphatic system is the clearance of the brain parenchyma from metabolic leftovers and interstitial solutes including beta amyloid. Decreased brain clearance venous sinuses, and hydrocephalus. Sleep apneas also cause fragmentation of the sleep architecture (top central image, left arrow) with arousals and awakening, as well as lack of REM sleep. Absence of REM sleep is accompanied by decreased glymphatic circulation of CSF, which contributes to hydrocephalus. The metabolic consequences of the sleep apnea syndrome are illustrated on the right side of the diagram and result from sympathetic activation, with tachycardia, hypertension, activation of coagulation mechanisms, and systemic inflammatory responses that increase the risk of cardiac arrhythmias, sudden death, and stroke

may contribute to the development of neurodegenerative diseases [91].

In patients with iNPH, Hasan-Olive et al. [93] performed electron microscopy studies in cortical brain biopsies and demonstrated reduced density of AQP4 water channels in astrocytic end-foot membranes along cortical microvessels. Ringstad et al. [94.•] utilized intrathecal gadobutrol MRI in subjects with iNPH and observed delayed clearance of the CSF tracer due to resistance to glymphatic flow. Parenchymal glymphatic enhancement peaked overnight as an effect of sleep but glymphatic clearance was clearly decreased in iNPH patients. According to Ringstad et al. [94・•], the decreased glymphatic clearance explains the delayed periarterial enhancement of glymphatic flow and the 
Table 2 Pathophysiological mechanisms relevant to iNPH induced by apneas during sleep

- Recurrent hypoxemia (low $\mathrm{PaO}_{2}$ ) hypercapnia (elevated $\mathrm{PaCO}_{2}$ ) and respiratory acidosis (low blood $\mathrm{pH}$ )

- Activation of carotid and aortic chemoreceptors

- Stimulation of rostral pontine respiratory neurons

- Firing of solitary tract nucleus neurons, dorsal medullary respiratory group, and ventral group nucleus ambiguus

- Repeated reflex contractions of respiratory chest and abdominal muscles

- Thoracoabdominal excursions greatly increase negative intrathoracic pressure

- Superior vena cava and intracranial venous hypertension in the dural sinuses

Decreased CSF absorption through Pacchionian granulations (arachnoid villae)

Tachycardia from atrial Bainbridge reflex

- Sympathetic (adrenergic) outburst

Arterial hypertension

Baroreceptor reflex activation

Peripheral vasoconstriction

Hyperglycemia

Hypercoagulability

- Inflammation from recirculation of hypoxic-acidotic blood

C-reactive protein (CRP)

Nuclear factor-kB (NF-kB)

Hyperhomocysteinemia

Interleukin-6 (IL-6)

Tumor necrosis factor alpha $(\mathrm{TNF}-\alpha)$

reflux of gadobutrol into the lateral ventricles typical of iNPH. Reduced glymphatic function probably related to abnormal sleep resulting from SDB may be instrumental in the pathogenesis of iNPH.

\section{Conclusions}

The pathogenesis of iNPH has remained enigmatic during the half century since its description. However, the association of SDB and iNPH was well documented and studied in the years that followed the first accounts of these two conditions in $1965[24 \bullet, 30 \bullet$. The pathophysiological interactions between respiration and CSF circulation have been solidly established since then [66]. However, those earlier observations were essentially forgotten until we rediscovered the interaction by the systematic assessment of sleep in all patients evaluated at our Memory Disorders and Dementia Clinic [18••]. Recent and future discoveries of sleep physiology relevant to cognitive disorders of aging should continue to increase our understanding of iNPH perhaps opening new venues for treatment and prevention.
Acknowledgments Dr. Gustavo Roman's research is supported by The Jack S. Blanton Presidential Distinguished Chair, the Fondren Fund, and the Wareing Family Fund at Houston Methodist Hospital. We acknowledge the collaboration of Matthew G. Landry, medical artist, at Houston Methodist Hospital Research Institute.

\section{Compliance with Ethical Standards}

Conflict of Interest Gustavo C. Román, Robert E. Jackson, Steve H. Fung, Y. Jonathan Zhang, and Aparajitha K. Verma each declare no potential conflicts of interest.

Human and Animal Rights and Informed Consent The original studies on the link of iNPH and SDB were approved by Houston Methodist Hospital Research Institute (IRB: Pro0011385). This article does not contain any studies with animal subjects performed by any of the authors.

Open Access This article is distributed under the terms of the Creative Commons Attribution 4.0 International License (http:// creativecommons.org/licenses/by/4.0/), which permits unrestricted use, distribution, and reproduction in any medium, provided you give appropriate credit to the original author(s) and the source, provide a link to the Creative Commons license, and indicate if changes were made.

\section{References}

Papers of particular interest, published recently, have been highlighted as:

- Of importance

•. Of major importance

1. Leng Y, Musiek ES, Hu K, Cappuccio FP, Yaffe K. Association between circadian rhythms and neurodegenerative diseases. Lancet Neurol. 2019;18:307-18. https://doi.org/10.1016/S1474-4422(18) 30461-7 This review addresses a novel topic of sleep research, i.e., circadian rhythms and neurodegeneration. Proposed pathways include protein homoeostasis, immunity, and inflammation. Further research and clinical trials are needed for the potential prevention and treatment of neurodegenerative diseases.

2. Scullin MK, Gao C, Fillmore P, Roberts RL, Pruett N, Bliwise DL. REM sleep mediates age-related decline in prospective memory consolidation. Sleep. 2019; pii:zsz055. https://doi.org/10.1093/ sleep/zsz055.

3. Fine L, Weinborn M, Ng A, Loft S, Li YR, Hodgson E, et al. Sleep disruption explains age-related prospective memory deficits: implications for cognitive aging and intervention. Neuropsychol Dev Cogn B Aging Neuropsychol Cogn. 2018 Aug;30:1-16. https:// doi.org/10.1080/13825585.2018.1513449.

4. Sindi S, Johansson L, Skoog J, Mattsson AD, Sjöberg L, Wang HX, et al. Sleep disturbances and later cognitive status: a multi-centre study. Sleep Med. 2018;52:26-33. https://doi.org/10.1016/j.sleep. 2017.11.1149.

5. Jackson ML, Howard ME, Barnes M. Cognition and daytime functioning in sleep related breathing disorders. Prog Brain Res. 2011;190:53-68.

6. Lal C, Strange C, Bachman D. Neurocognitive impairment in obstructive sleep apnea. Chest. 2012;141:1601-10.

7. Olaithe M, Bucks RS. Executive dysfunction in OSA before and after treatment: a meta-analysis. Sleep. 2013;36:1297-305. 
8. Kim HC, Young T, Matthews CG, Weber SM, Woodward AR, Palta M. Sleep disordered breathing and neuropsychological deficits: a population-based study. Am J Respir Crit Care Med. 1997; 156:1813-9.

9. Gildner TE, Liebert MA, Kowal P, Chatterji S, Snodgrass JJ. Associations between sleep duration, sleep quality, and cognitive test performance among older adults from six middle-income countries: results from the study on global ageing and adult health (SAGE). J Clin Sleep Med. 2014;10:613-21.

10. Aoki K, Matsuo M, Takahashi M, Murakami J, Aoki Y, Aoki N, et al. Association of sleep-disordered breathing with decreased cognitive function among patients with dementia. J Sleep Res. 2014;23:517-23. https://doi.org/10.1111/jsr.12167.

11. Shi L, Chen SJ, Ma MY, Bao YP, Han Y, Wang YM, et al. Sleep disturbances increase the risk of dementia: a systematic review and meta-analysis. Sleep Med Rev. 2018;40:4-16. https://doi.org/10. 1016/j.smrv.2017.06.010.

12. Leng Y, CT ME, Allen IE, Yaffe K. Association of sleep-disordered breathing with cognitive function and risk of cognitive impairment: a systematic review and meta-analysis. JAMA Neurol. 2017;74(10): 1237-45. https://doi.org/10.1001/jamaneurol.2017 2180 This systematic review and meta-analysis of 14 studies included a total of 4,288,419 men and women. SDB increased $26 \%$ (risk ratio, 1 . 26; 95\% CI, 1.05-1.50) the risk of cognitive impairment. The pooled risk ratio was 1.35 (95\% CI, 1.11-1.65).

13. Bubu OM, Pirraglia E, Andrade AG, Sharma RA, Gimenez-Badia S, Umasabor-Bubu OQ, et al. Obstructive sleep apnea and longitudinal Alzheimer's disease biomarker changes. Sleep. 2019:pii: zsz048. https://doi.org/10.1093/sleep/zsz048.

14. Carnicelli L, Maestri M, Di Coscio E, Tognoni G, Fabbrini M, Schirru A, et al. A longitudinal study of polysomnographic variables in patients with mild cognitive impairment converting to Alzheimer's disease. J Sleep Res. 2019:e12821. https://doi.org/10. 1111 /jsr. 12821.

15. Zhang F, Zhong R, Li S, Fu Z, Wang R, Wang T, et al. Alteration in sleep architecture and electroencephalogram as an early sign of Alzheimer's disease preceding the disease pathology and cognitive decline. Alzheimers Dement . 2019 Feb 25. pii: S15525260(18)33621-5. https://doi.org/10.1016/j.jalz.2018.12.004.

16. Williams MA, Malm J. Diagnosis and treatment of idiopathic normal pressure hydrocephalus. Continuum (Minneapolis, Minnesota). 2016;22:579-99 This is an excellent update on the topic of iNPH with didactic comprehensive texts, illustrative images, and clinical examples.

17. Malm J, Graff-Radford NR, Ishikawa M, Kristensen B, Leinonen V, Mori E, et al. Influence of comorbidities in idiopathic normal pressure hydrocephalus - research and clinical care. A report of the ISHCSF task force on comorbidities in iNPH. Fluids Barriers CNS. 2013;10:22. https://doi.org/10.1186/2045-8118-10-22.

18.•• Román GC, Verma AK, Zhang YJ, Fung SH. Idiopathic normalpressure hydrocephalus and obstructive sleep apnea are frequently associated: a prospective cohort study. J Neurol Sci. 2018;395:1648. https://doi.org/10.1016/j.jns.2018.10.005 This paper is the first recent description of SDB in patients with iNPH. We found OSA in $90.3 \%(28 / 31)$ patients with iNPH; all had undiagnosed sleep abnormalities. Polysomnograms showed moderate-to-severe OSA in $80.6 \%$ with mean apneahypopnea index $(\mathrm{AHI})=31.6$; mean respiratory distress index $(\mathrm{RDI})=34.5 / \mathrm{h}$ and mean $\mathrm{SaO}_{2}$ desaturation at nadir $=82.2 \%$. The observed OSA prevalence is highly significant: $\mathbf{9 0 . 3 \%}$, 95\% CI 74.3-97.5 $p=\mathbf{0 . 0 0 0 , 0 0 7}$. OSA probably contributes to other vascular risk factors including overweight body mass index in $59 \%$, hyperhomocysteinemia $57 \%$, hypertension $43 \%$, hyperlipidemia $39 \%$, diabetes $32 \%$, smoking $21 \%$, coronary disease $18 \%$, and previous stroke $10 \%$.
19. Damasceno BP. Neuroimaging in normal pressure hydrocephalus. Dement Neuropsychol. 2015;9:350-5.

20. Virhammar J, Laurell K, Cesarini KG, Larsson E-M. The callosal angle measured on MRI as a predictor of outcome in idiopathic normal-pressure hydrocephalus. J Neurosurg. 2014;120:178-84.

21. Hashimoto M, Ishikawa M, Mori E, Kuwana N, for the study of INPH on neurological improvement (SINPHONI). Diagnosis of idiopathic normal pressure hydrocephalus is supported by MRIbased scheme: a prospective cohort study. Cerebrospinal Fluid Res. 2010;7:18.

22. Mori E, Ishikawa M, Kato T, Kazui H, Miyake H, Miyajima M, et al. Guidelines for management of idiopathic normal pressure hydrocephalus: second edition. Neurol Med Chir (Tokyo). 2012;52:775-809.

23. Kelly EJ, Yamada S. Cerebrospinal fluid flow studies and recent advancements. Semin Ultrasound CT MR. 2016;37:92-9. https:// doi.org/10.1053/j.sult.2016.01.002.

24. Hakim S, Adams RD. The special clinical problem of symptomatic hydrocephalus with normal cerebrospinal fluid pressure. Observations on cerebrospinal fluid hydrodynamics. J Neurol Sci. 1965:2:307-27 This is the first description of NPH with detailed accounts of clinical and imaging features. Cases of symptomatic NPH as well as iNPH were included. The physiopathology is considered to be the result of Pascal's law of hydrodynamics.

25. Román GC. Frequent falls in the elderly: think NPH! Texas Neurological Society Broca's Area. 2016;(Summer):8-10.

26. Houry D, Florence C, Baldwin G, Stevens J, McClure R. The CDC injury center's response to the growing public health problem of falls among older adults. Am J Lifestyle Med. 2016;10(1):74-7. https://doi.org/10.1177/1559827615600137.

27. Foldvary-Schaefer NR, Waters TE. Sleep-disordered breathing. Continuum (Minneapolis, Minnesota). 2017;23:1093-116 This article is an excellent update on the epidemiology, diagnostic criteria, clinical manifestations, and diagnostic procedures used to diagnose SDB. The author provides a detailed review of the physiopathological changes caused by OSA and the positive effects of the treatment.

28. Somers VK, White DP, Amin R, Abraham WT, Costa F, Culebras A, et al. Sleep apnea and cardiovascular disease: an American Heart Association/American College of Cardiology Foundation scientific statement from the American Heart Association Council for High Blood Pressure Research Professional Education Committee, Council on Clinical Cardiology, Stroke Council, and Council on Cardiovascular Nursing. Circulation. 2008;118:1080-111.

29. Baltzis D, Bakker JP, Patel SR, Veves A. Obstructive sleep apnea and vascular diseases. Compr Physiol. 2016;6:1519-28. https://doi. org/10.1002/cphy.c150029.

30. Gastaut H, Tassinari CA, Duron B. Étude polygraphique des manifestations épisodiques (hypniques et respiratoires) du syndrome de Pickwick. Rev Neurol (Paris). 1965;112:568-79 This is the original description of OSA in a single patient. From a rare condition, OSA has become a common problem worldwide.

31. Senaratna CV, Perret JL, Lodge CJ, Lowe AJ, Campbell BE, Matheson MC, et al. Prevalence of obstructive sleep apnea in the general population: a systematic review. Sleep Med Rev. 2017;34: $70-81$

32. Lee SD, Kang SH, Ju G, Han JW, Kim TH, Lee CS, et al. The prevalence of and risk factors for sleep-disordered breathing in an elderly Korean population. Respiration. 2014;87:372-8.

33. Heinzer R, Vat S, Marques-Vidal P, Marti-Soler H, Andries D, Tobback N, et al. Prevalence of sleep-disordered breathing in the general population: the HypnoLaus study. Lancet Respir Med. 2015;3:310-8.

34. Drager LF, Togeiro SM, Polotsky VY, Lorenzi-Filho G. Obstructive sleep apnea: a cardiometabolic risk in obesity and the metabolic syndrome. J Am Coll Cardiol. 2013;62:569-76. 
35. Guillot M, Sforza E, Achour-Crawford E, Maudoux D, SaintMartin M, Barthélemy JC, et al. Association between severe obstructive sleep apnea and incident arterial hypertension in the older people population. Sleep Med. 2013;14:838-42.

36. Konecny T, Kara T, Somers VK. Obstructive sleep apnea and hypertension: an update. Hypertension. 2014;63:203-9.

37. Aurora RN, Punjabi NM. Obstructive sleep apnoea and type 2 diabetes mellitus: a bidirectional association. Lancet Respir Med. 2013;1:329-38.

38. Yoshihisa A, Takeishi Y. Sleep disordered breathing and cardiovascular diseases. J Atheroscler Thromb. 2019. https://doi.org/10. 5551/jat.RV1703.

39. Geovanini GR, Lorenzi-Filho G. Cardiac rhythm disorders in obstructive sleep apnea. J Thorac Dis. 2018;10 (Suppl. 34:S4221-30. https://doi.org/10.21037/jtd.2018.12.63.

40. Eysenck W, Sulke N, Freemantle N, Patel NR, Furniss SS, Veasey RA. The effect of atrial fibrillation intervention on nocturnal respiratory events in elderly patients with persistent AF. Clin Respir J. 2019. https://doi.org/10.1111/crj.13008.

41. La Rovere MT, Fanfulla F, Taurino AE, Bruschi C, Maestri R, Robbi E, et al. Chronic thromboembolic pulmonary hypertension: reversal of pulmonary hypertension but not sleep disordered breathing following pulmonary endarterectomy. Int J Cardiol. 2018;264: 147-52. https://doi.org/10.1016/j.ijcard.2018.02.112.

42. Nakamoto T. Sleep-disordered breathing - a real therapeutic target for hypertension, pulmonary hypertension, ischemic heart disease, and chronic heart failure? J Nippon Med Sch. 2018;85:70-7. https://doi.org/10.1272/jnms.2018 85-12.

43. Seiler A, Camilo M, Korostovtseva L, Haynes AG, Brill AK, Horvath T, et al. Prevalence of sleep-disordered breathing after stroke and TIA: a meta-analysis. Neurology. 2019;92(7):e648-54. https://doi.org/10.1212/WNL.0000000000006904.

44. Cooper R, Hulme A. Intracranial pressure and related phenomena during sleep. J Neurol Neurosurg Psychiatry. 1966;29: 564-70.

45. Ogashiwa M, Takeuchi K. Intracranial pressure changes during sleep in man. No To Shinkei. 1983;35:123-9.

46. Yokota A, Matsuoka S, Ishikawa T, Kohshi K, Kajiwara H. Overnight recordings of intracranial pressure and electroencephalography in neurosurgical patients. Part II: changes in intracranial pressure during sleep. Sangyo Ika Daigaku Zasshi. 1989;11:383-91.

47. Meyer JS, Gotham J, Tazaki Y, Gotoh F. Cardiorespiratory syndrome of extreme obesity with papilledema. Report of a fatal case with electroencephalographic, metabolic, and necropsy studies. Neurology. 1961;11:950-8.

48. Lugaresi E, Coccagna G, Cirignotta F, Farneti P, Gallassi R, Di Donato $\mathrm{G}$, et al. Breathing during sleep in man in normal and pathological conditions. Adv Exp Med Biol. 1978;99:35-45.

49. Iijima S, Sugita Y, Hishikawa Y, Teshima Y. Arterial blood gas analysis during sleep in a patient with sleep apnea syndrome. Jap J EEG EMG. 1979;7:64.

50. Kaneda H, Hayashi H, Shimizu T, Teshima Y, Sugita S, Hishikawa Y. Sleep apnea and B wave of CSF pressure in patients with dementia. Jap J EEG EMG. 1983;11:58.

51. Kuchiwaki H, Gonda T, Hirai N, Inao I, Takeda M, Kageyama N, et al. Sleep and intracranial pressure change in patients with normal pressure hydrocephalus. Jap J EEG EMG. 1983;11:58.

52. Kuchiwaki H, Kageyama N, Hirai N, Takada S, Inao S, Terashima M. A biological rhythm in a patient with normal pressure hydrocephalus - comparative studies in pre- and postoperative patients by polygraphy. No To Shinkei. 1984;36:911-6.

53. Kuchiwaki H, Takada S, Ishiguiri H, Kageyama N, Terashima M, Furuse M, et al. Pressure wave with apnea evaluated by sleep level in patients with ventricular dilatation. Neurol Res. 1988;10:105-11.
54. Sugita Y, Iijima S, Teshima Y, Shimizu T, Nishimura N, Tsutsumi T, et al. Marked episodic elevation of cerebrospinal fluid pressure during nocturnal sleep in patients with sleep apnea hypersomnia syndrome. Electroencephalogr Clin Neurophysiol. 1985;60:214-9.

55. Jennum P, Børgesen SE. Intracranial pressure and obstructive sleep apnea. Chest. 1989;95:279-83.

56. Pasterkamp H, Cardoso ER, Booth FA. Obstructive sleep apnea leading to increased intracranial pressure in a patient with hydrocephalus and syringomyelia. Chest. 1989;95:1064-7.

57. McNamara ME, Millman RP, Epstein MH. The association of normal-pressure hydrocephalus with obstructive sleep apnoea. J Geriatr Psychiatry Neurol. 1992;5:238-40.

58. Krauss JK, Droste DW, Bohus M, Regel JP, Scheremet R, Riemann $\mathrm{D}$, et al. The relation of intracranial pressure B-waves to different sleep stages in patients with suspected normal pressure hydrocephalus. Acta Neurochir. 1995;136:195-203.

59. Kristensen B, Malm J, Rabben T. Effects of transient and persistent cerebrospinal fluid drainage on sleep disordered breathing in patients with idiopathic adult hydrocephalus syndrome. J Neurol Neurosurg Psychiatry. 1998;65:497-501.

60. Tsunoda A, Mitsuoka H, Bandai H, Endo T, Arai H, Sato K. Intracranial cerebrospinal fluid measurement studies in suspected idiopathic normal pressure hydrocephalus, secondary normal pressure hydrocephalus, and brain atrophy. J Neurol Neurosurg Psychiatry. 2002;73:552-5.

61. Milhorat TH. The third circulation revisited. J Neurosurg. 1975;42: 628-45.

62. Williams H. The venous hypothesis of hydrocephalus. Med Hypotheses. 2008;70:743-7.

63. El Sankari S, Gondry-Jouet C, Fichten A, Godefroy O, Serot JM, Deramond H. Cerebrospinal fluid and blood flow in mild cognitive impairment and Alzheimer's disease: a differential diagnosis from idiopathic normal pressure hydrocephalus. Fluids Barriers CNS. 2011;8:12. https://doi.org/10.1186/2045-8118-8-12.

64. Brinker T, Stopa E, Morrison J, Klinge P. A new look at cerebrospinal fluid circulation. Fluids Barriers CNS. 2014;11:10. https:// doi.org/10.1186/2045-8118-11-10.

65. Satow T, Aso T, Nishida S, Komuro T, Ueno T, Oishi N, et al. Alteration of venous drainage route in idiopathic normal pressure hydrocephalus and normal aging. Front Aging Neurosci. 2017;9: 387. https://doi.org/10.3389/fnagi.2017.00387.

66. Román GC. Pathogenesis of cerebral small-vessel disease in obstructive sleep apnea. In: Culebras A, editor. Sleep, stroke, and cardiovascular disease. Cambridge: Cambridge University Press; 2013. p. 97-103.

67. López-Jiménez F, Sert Kuniyoshi FH, Gami A, Somers VK. Obstructive sleep apnea: implications for cardiac and vascular disease. Chest. 2008;133:793-804.

68. McNicholas WT, Javaheri S. Pathophysiologic mechanisms of cardiovascular disease in obstructive sleep apnea. Sleep Med Clin. 2007;2:539-47.

69. Lurie A. Hemodynamic and autonomic changes in adults with obstructive sleep apnea. Adv Cardiol. 2011;46:171-95.

70. Lévy P, Kohler M, McNicholas WT, Barbé F, McEvoy RD, Somers VK, et al. Obstructive sleep apnoea syndrome. Nat Rev Dis Primers 2015 Jun. 2015;25(1):15015. https://doi.org/10.1038/nrdp.2015. 15.

71. Destors M, Tamisier R, Galerneau LM, Lévy P, Pepin JL. Pathophysiology of obstructive sleep apnea syndrome and its cardiometabolic consequences. Presse Med. 2017;46:395-403. https://doi.org/10.1016/j.lpm.2016.09.008.

72. Guyenet PG. Neural structures that mediate sympathoexcitation during hypoxia. Resp Physiol. 2000;121:147-62.

73. Guyenet PG, Bayliss DA, Mulkey DK, Stornetta RL, Moreira TS, Takakura AT. The retrotrapezoid nucleus and central chemoreception. Adv Exp Med Biol. 2008;605:327-32. 
74. Desteghe L, Hendriks JML, McEvoy RD, Chai-Coetzer CL, Dendale P, Sanders P, et al. The why, when and how to test for obstructive sleep apnea in patients with atrial fibrillation. Clin Res Cardiol. 2018;107:617-31.

75. Somers VK, Dyken ME, Clary MP, Abboud FM. Sympathetic neural mechanisms in obstructive sleep apnea. J Clin Invest. 1995;96: 1897-904.

76. Gilmartin GS, Lynch M, Tamisier R, Weiss JW. Chronic intermittent hypoxia in humans during 28 nights results in blood pressure elevation and increased muscle sympathetic nerve activity. Am J Physiol Heart Circ Physiol. 2010;299:H925-31. https://doi.org/10. 1152/ajpheart.00253.2009.

77. Shamsuzzaman A, Amin RS, Calvin AD, Davison D, Somers VK. Severity of obstructive sleep apnea is associated with elevated plasma fibrinogen in otherwise healthy patients. Sleep Breath. 2014;18: 761-6. https://doi.org/10.1007/s11325-014-0938-4.

78. Pedrosa RP, Drager LF, Gonzaga CC, Sousa MG, de Paula LK, Amaro AC, et al. Obstructive sleep apnea: the most common secondary cause of hypertension associated with resistant hypertension. Hypertension. 2011;58:811-7.

79. Li K, Wei P, Qin Y, Wei Y. Is C-reactive protein a marker of obstructive sleep apnea? A meta-analysis. Medicine (Baltimore). 2017;96:e6850.

80. Li K, Zhang J, Qin Y, Wei YX. Association between serum homocysteine level and obstructive sleep apnea: a meta-analysis. Biomed Res Int. 2017;7234528. https://doi.org/10.1155/2017/723452.

81. Wallin A, Román GC, Esiri M, Kettunen P, Svensson J, Paraskevas GP, et al. Update on vascular cognitive impairment associated with subcortical small-vessel disease. J Alzheimers Dis. 2018;62:141741. https://doi.org/10.3233/JAD-170803.

82. Wong HS, Williams AJ, Mok Y. The relationship between pulmonary hypertension and obstructive sleep apnea. Curr Opin Pulm Med. 2017;23:517-21. https://doi.org/10.1097/MCP. 0000000000000421 .

83. Apuzzo JL, Weiss MH, Petersons V, Small RB, Kurze T, Heiden JS. Effect of positive end-expiratory pressure on intracranial pressure in man. J Neurosurg. 1977;46:227-32.

84. Muench E, Bauhuf C, Roth H, Horn P, Phillips M, Marquetant N, et al. Effects of positive end-expiratory pressure on regional cerebral blood flow, intracranial pressure, and brain tissue oxygenation. Crit Care Med. 2005;33:2367-72.

85. Yiallourou TI, Schmid Daners M, Kurtcuoglu V, Haba-Rubio J, Heinzer R, Fornari E, et al. Continuous positive airway pressure alters cranial blood flow and cerebrospinal fluid dynamics at the craniovertebral junction. Interdiscip Neurosurg. 2015;2:152-9.
86. Frydrychowski AF, Winklewski PJ, Guminski W. Influence of acute jugular vein compression on the cerebral blood flow velocity, pial artery pulsation and width of subarachnoid space in humans. PLoS One. 2012;7:e48245.

87. Lee AG, Golnik K, Kardon R, Wall M, Eggenberger E, Yedavally S. Sleep apnea and intracranial hypertension in men. Ophthalmology. 2002;109:482-5.

88. Purvin VA, Kawasaki A, Yee RD. Papilledema and obstructive sleep apnea syndrome. Arch Ophthalmol. 2000;118:1626-30.

89.•• JJ I, Wang M, Liao Y, Plogg BA, Peng W, Gundersen GA, et al. A paravascular pathway facilitates CSF flow through the brain parenchyma and the clearance of interstitial solutes, including amyloid beta. Sci Transl Med. 2012;4:147ra111 This paper reporting the discovery of the glymphatic system in rodents opened a new and unexpected chapter into the physiology of the CSF and the interstitial circulation in the brain.

90.• Xie L, Kang H, Xu Q, Chen MJ, Liao Y, Thiyagarajan M, et al. Sleep drives metabolite clearance from the adult brain. Science. 2013;342:373-7 The authors demonstrated that one of the main functions of the glymphatic system during sleep is clearance of metabolic debris from the brain. Research on the importance of the glymphatic circulation in neurodegenerative conditions and iNPH is just beginning.

91. Rasmussen MK, Mestre H, Nedergaard M. The glymphatic pathway in neurological disorders. Lancet Neurol. 2018;17(11):101624. https://doi.org/10.1016/S1474-4422(18)30318-1.

92. Desai B, Hsu Y, Schneller B, Hobbs JG, Mehta AI, Linninger A. Hydrocephalus: the role of cerebral aquaporin-4 channels and computational modeling considerations of cerebrospinal fluid. Neurosurg Focus. 2016;41(3):E8. https://doi.org/10.3171/2016.7. FOCUS16191.

93. Hasan-Olive MM, Enger R, Hansson HA, Nagelhus EA, Eide PK. Loss of perivascular aquaporin-4 in idiopathic normal pressure hydrocephalus. Glia. 2018 Oct 10;67:91-100. https://doi.org/10.1002/ glia.23528.

94.• Ringstad G, SAS V, Eide PK. Glymphatic MRI in idiopathic normal pressure hydrocephalus. Brain. 2017;140(10):2691-70 This paper demonstrated the presence of reduced glymphatic circulation in patients with iNPH. Furthermore, it confirmed the existence and function of the glymphatic system in humans.

Publisher's Note Springer Nature remains neutral with regard to jurisdictional claims in published maps and institutional affiliations. 